\title{
The gap between self-reported and actual contributions to climate change mitigation in US residents
}

\author{
Giangiacomo Bravo, Mike Farjam ${ }^{\dagger}$
}

\begin{abstract}
Survey measures of environmental concern are known to only weakly predict self-reported environmental behaviour. In addition, self-reported and actual behaviour may not match in empirical settings. To better explore the relations among these variables and their connection to the political stance of participants, we ran an online experiment with 805 US residents. Four key variables - environmental concern, self-reported environmental behaviour, observed environmental behaviour (in the form of carbon compensation), and political attitudes - were measured and their interactions in promoting pro-environmental behaviour were analysed. We found that self-reported measures hardly held any correlation with real behaviour and that political attitudes mainly predicted self-reported measures, not real environmental behaviour.
\end{abstract}

Keywords: environmental behaviour; experiment; attitude-behaviour gap

\section{Introduction}

It has long been found that people do not put their money where their mouth is, i.e. the correlation between stated attitudes and real behaviour is at best low (Jerolmack \& Khan 2014). This mismatch becomes particularly problematic when it comes to the implementation of environmental policies (Sebbane \& Costa 2018; Lange \& Dewitte 2019), where stating a pro-environmental attitude or behavioural intention may be perceived as socially desirable (Carrington et al. 2010; Krumpal 2011). We present results of an online experiment testing how and to which extend attitudes, political preferences, self-reported behaviour, and actual behaviour relate to each other in an environmental context.

Many studies estimate the effectiveness of environmental policy by either measuring changes in environmental attitudes or changes in self-reported behaviour. Measures of environmental concern in surveys are know to only weakly predict the behaviour reported in the same studies (Kollmuss \& Agyeman 2002; Flynn et al. 2009; Peattie 2010; Carrington et al. 2014; Hassan et al. 2014). Even worse, self-reported and actual behaviour do not necessarily match in real world settings (Sebbane \& Costa 2018; Lange \& Dewitte 2019). This effect is especially relevant in the context of climate change mitigation (Fielding \& Hornsey 2016), where evidence shows that even concerned people systematically fail to reduce their carbon footprint (Lorenzoni et al. 2007; Whitmarsh 2009), and most policy makers do not even dare to propose to the public the most effective actions, possibly fearing their unpopularity (Wynes \& Nicholas 2017). To design and evaluate efficient climate change mitigation policies, it is thus crucial to understand to what extend self-reported data can predict real behaviour and under which circumstances measurements of real behaviour - often more difficult to realise - are needed for a proper evaluation.

\footnotetext{
${ }^{*}$ Department of Social Studies and Centre for Data Intensive Sciences and Applications, Linnaeus University, Växjö, Sweden

${ }^{\dagger}$ Department of Computer Science and Media Technology and Centre for Data Intensive Sciences and Applications, Linnaeus University, Växjö, Sweden
} 
Unlike previous studies on the attitude-behaviour gap in environmental contexts, our experiment includes both a questionnaire on environmental attitudes and self-reported behaviour and an incentivized decision - i.e., a decision that had real financial consequences for participants where subjects could decide to give up part of their financial compensation for participating in the experiment and instead donate that money to offset their real-life carbon emissions. Our setup is thus unique in that it allows to estimate the relationship between measurements commonly obtained in surveys and costly environmental behaviour with real-world consequences under controlled experimental conditions.

Environmental issues, and in particular climate change, are heavily politicised, that is, the inherent uncertainty in scientific evidence has been exaggerated to support political agendas (Bolsen \& Druckman 2015). It is thus not surprising that research found that political orientation predicts environmental attitudes and behaviour, at least in the American context (Cruz 2017; Farjam 2020). Therefore, we also measured the political stance of participants in the experiment. Additionally, we systematically varied the cost they had to pay to offset carbon emissions. This allowed to asses how the cost of the environmental behaviour moderates the relation between environmental behaviour and attitudes. Previous research found that attitudes become less predictive for behaviour, as the costs for that behaviour increase (Farjam et al. 2019), the so called low-cost hypothesis of environmental behaviour (Diekmann \& Preisendörfer 1998, 2003). Put together, all these variables shed light on the complex relations among demographic, economic and political variables and how they moderate the attitude behaviour gap in environmental contexts.

\section{Methods}

We implemented a behavioural experiment using the oTree platform (Chen et al. 2016). On November 26, 2019, a total of 805 participants were recruited through Amazon's Mechanical Turk (MTurk) and completed all tasks. They received an average compensation of 4.6 USD for their work, of which 2.5 USD was a flat payment given to all participants and the remainder depended on their choices. The entire experiment took on average 15 minutes. Before admission to the experiment participants read general instructions and answered control questions to check their understanding of the task and to filter out automated bots. Participation was only possible from US IP-addresses.

In the instructions, participants learned that they would have to answer a questionnaire related to environmental issues. Furthermore, they were endowed with $100 \mathrm{ECU}$ (Experimental Currency Units) and later during the experiment had to decide how many of these they wanted to contribute to offset carbon emissions through the United Nations platform for voluntary cancellation of certified emissions reductions (CERs). If wanted, they could enter their email address at the end of the experiment to receive a confirmation of the amount of carbon offset as a result of the experiment. However, leaving the email address was absolutely optional and subjects were informed that the addresses would be saved in a separate database. To simulate different costs linked to environmental behaviour, the actual value of the ECU differed across treatments: with 100 ECU being worth between 1 and 10 USD. Only if the control questions were answered correctly, the participants could enter the experiment. The full set of instructions and other materials used in the experiment can be found in Appendix A.1, while Appendix A.2 shows sample descriptive statistics for each treatment.

To ensure that the order of tasks in the experiment did not systematically affect answers or contributions, all tasks (three blocks of questions and one contribution question) were presented in random order. The three sections of the questionnaire, correspond to three selected dimensions of the Environmental Attitudes Inventory (EAI) (Milfont \& Duckitt 2010), a scale commonly used in surveys. The selected dimensions were Environmental Threat, Ecocentric Concern, and Per- 
sonal Conservation Behaviour (full set of questions in Appendix A.3). In a separate contribution section, participants were reminded that they were endowed with 100 ECUs and of the ECU value in USD. In addition, the page included a link to the UN-CERs platform, where participants could familiarise themselves with the organisation and the proposed carbon compensation projects. Participants then could contribute any amount between 0 and 100 ECUs through a slider, knowing that the part of the endowment not contributed to carbon compensation would be added to the compensation that they would receive for participation in the experiment. We chose to make the participants contribute in ECUs instead of USD to make the donation process identical across treatments despite different ECU to USD ratios. In total participants contributed 740 USD, which were used to offset $2114 \mathrm{t}$ of carbon.

The experiment concluded with a short demographic questionnaire and participants were asked to indicate their general political stance on a 0-10 left-right scale, as in Farjam et al. (2019). The average age of participants was 39 years $(\mathrm{SD}=12.3)$. The sample was relatively balanced in terms of gender (52\% men) but somewhat left-skewed in the political attitude of participants (median 4).

\section{Results}

\subsection{Self-reported behaviour vs. actual contributions}

As a first step in the analysis, we derived three latent factors from the battery items corresponding to the three dimensions considered from the Environmental Attitudes Inventory. Since the two factors measuring environmental concern (Environmental Threat and Ecocentric Concern) resulted to be strongly correlated $(r=0.68 ; p<0.01)$, we then extracted a single factor from all items included in the two scales (henceforth, simply Concern). The third factor was instead separately analysed (henceforth Self-reported behaviour). We then standardised the political stance and contribution variables, and computed the correlations among these measures (details of the analysis in the Appendix).

Fig. 1 shows the correlations of the four main variables measured in the experiment. The concern factor had a relatively high correlation with political stance, while it correlated somewhat less but still positively with self-reported behaviour. Interestingly, this correlation disappeared when considering actual behaviour, which in our case was the contribution to the carbon-offset scheme. The correlation between self-reported behaviour and actual contributions was extremely weak as well. Finally, the answers on the left-right scale (for a better readability higher values indicating a tendency to the left in our analysis) positively correlated with self-reported behaviour but not with contributions.

To test for interactions between our variables and to control for possible confounders, such as the participant's age and gender, and for the mediating role of our treatment variable (the contribution cost), we estimated a structural equation model (SEM) setting the contribution to the carbon offset scheme as the final outcome. The self-reported behaviour factor was introduced as mediator between the environmental concern and contributions. The standardised versions of the political stance and age were also used as predictors, along with the gender coded as $0=$ female and $1=$ male. Figure 2 summarises the structure and coefficient estimates of the resulting model (details and regression tables in Appendix A.5).

As common in surveys, the political stance and being male negatively affected environmental concern and other variables, while age only had a significant effect on self-reported behaviour. It is worth noting that, while concern significantly affected contributions, self reported behaviour did not. In other words, while concern did directly affect actual behaviour, this effect was not mediated by what people reported to do in their daily lives. This highlights a stronger gap between selfreported and actual behaviour than between concern and behaviour. Another surprising result was 


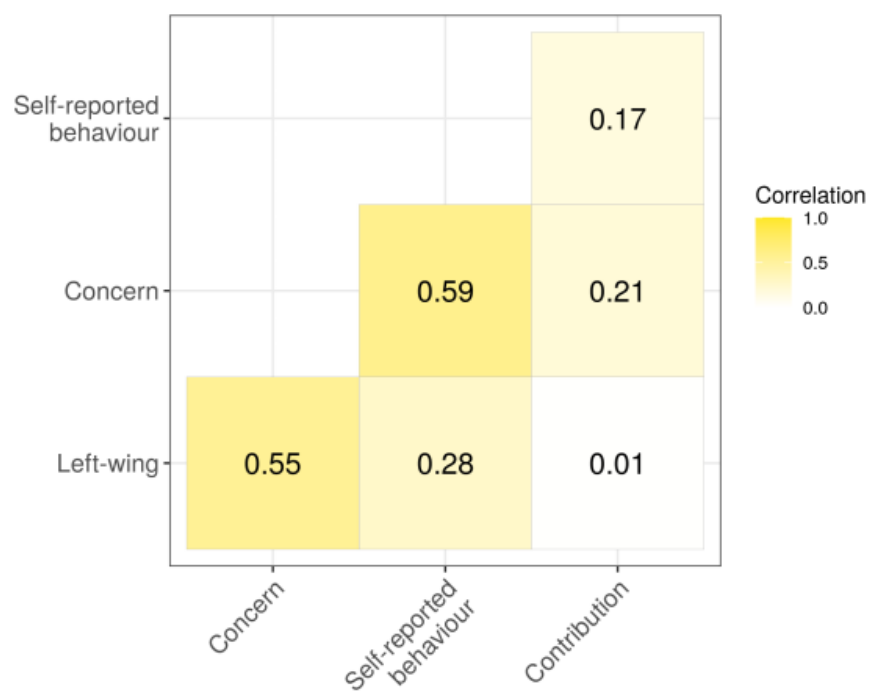

Figure 1: Matrix of correlations among the main variables.

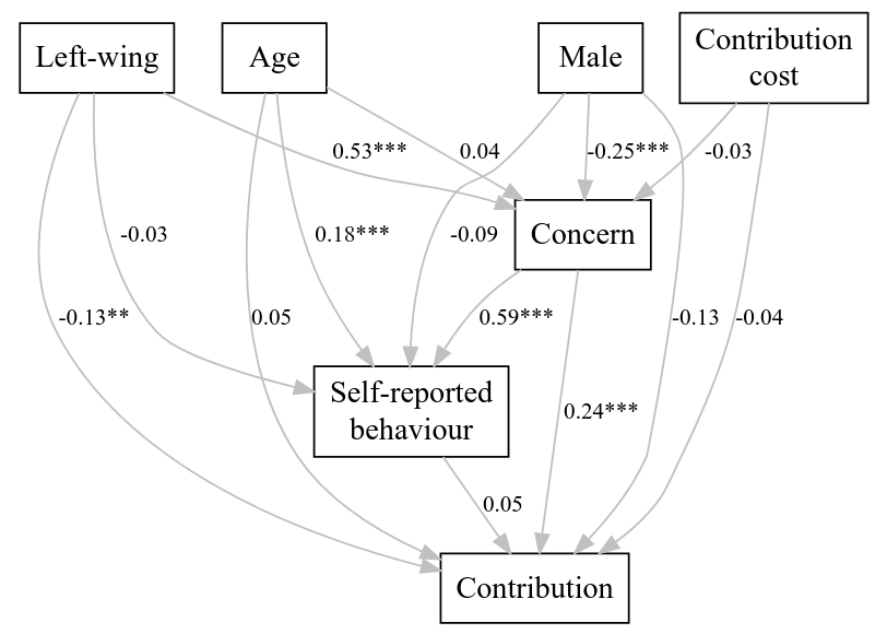

Figure 2: Structural equation model estimates. All variables were standardised.

that the political stance showed a small but significant negative effect on actual contributions (but not on self-reported behaviours). In other words, participants who positioned themselves more to the right of the political scale contributed more to the carbon-offset scheme after controlling for their concern, which was on average lower. Different from the predictions of the low-cost hypothesis, the contribution cost had no significant effect on contributions, neither directly nor through concern.

\subsection{Separate models by political stance}

Environmental attitudes and, in general, positions over environmental issues are known to intersect political affiliation in the USA (McCright et al. 2014; Farjam 2020). This was confirmed by the 
correlations in Figure 1 and the SEM analysis. To better analyse the differences between left- and right-wing participants, we split the dataset on the median of the political stance item. Participants were considered left-wing (or "liberals") if their score was higher than the median of this variable (400 individuals), right-wing (or "conservatives") otherwise (405 individuals). Given this split, liberals were younger ( $37.5 \pm 0.6$ vs. $40.2 \pm 0.6$ years old) and included a lower proportion of males $(0.49 \pm 0.03$ vs. $0.56 \pm 0.03)$. Not controlling for other variables, the differences between the two groups were large for environmental concern and self-reported behaviour (Fig. 3). However, the contrast between liberal and conservatives in actual contributions was much smaller and statistically non-significant (Wilcoxon rank sum test, $W=83994, p=0.351$ ).

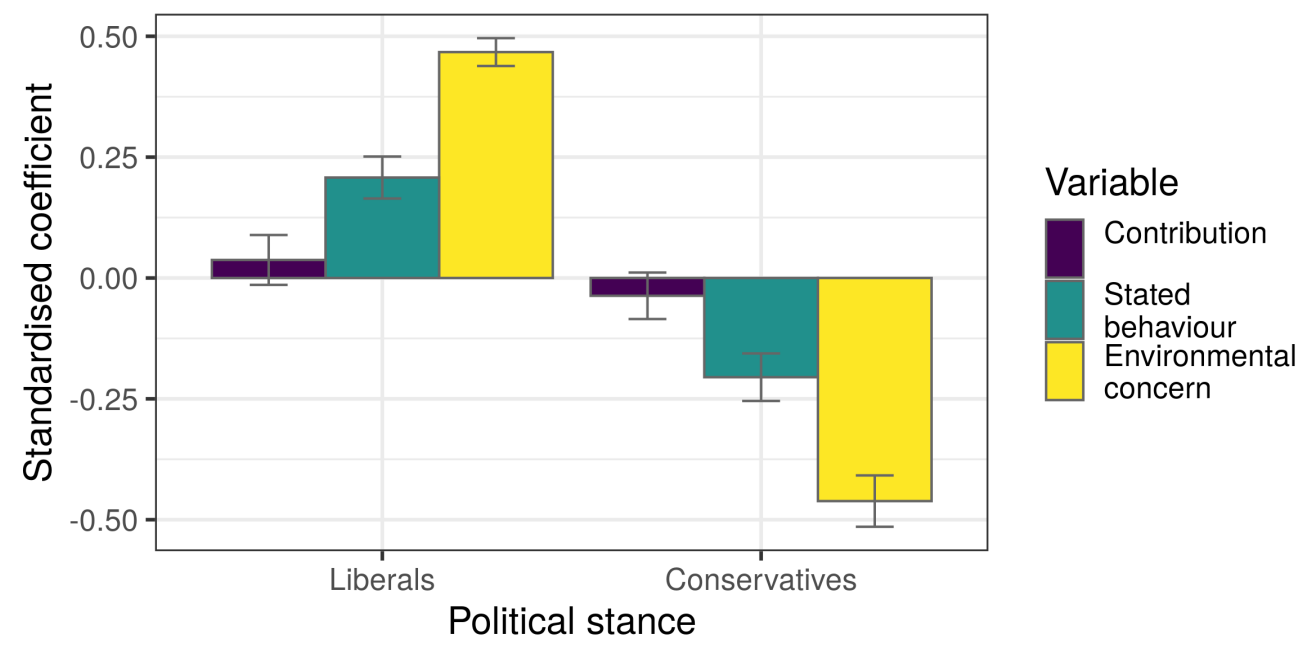

Figure 3: Means and standard errors by political stance for selected variables.

Although interesting in itself, this picture does not control for the different gender and age compositions of the two political groups and for the fact that highly-concerned right-wing people reported to do as much for the environment as left-wing ones, and even contributed slightly more to the purchasing of carbon-offset credits (Fig. 2). To better understand how political stance interacts with all other variables and provide a better picture of the differences between the two groups, we estimated separate SEM models for liberals and conservatives using a structure similar to the previous one, except for the omission of the left-wing variable. Figure 4 shows an overview of the resulting models, while details about the coefficient estimates are reported in Appendix A.5.

In both groups Concern strongly affected self-reported behaviour. However, its effect on actual contributions was only significant for conservatives, while for liberals this variable was only affected by the participant's age. It is also worth noting, that age affected concern for liberals, but not conservatives, while gender had a negative effect in both groups (although somewhat stronger in the latter).

\section{Discussion}

This paper shows that the relation between environmental concern, self-reported environmental behaviour, and actual contributions for climate change mitigation is at best week and is strongly mediated by demographic factors. The analysis of answers and actual behaviour of 805 US residents showed a strong attitude-behaviour gap, consistent with what is usually found in surveys (Kollmuss \& Agyeman 2002; Peattie 2010; Carrington et al. 2014). An even larger gap was found between self-reported and actual behaviour, to the point that information on the former was hardly 


\section{A) Liberals}

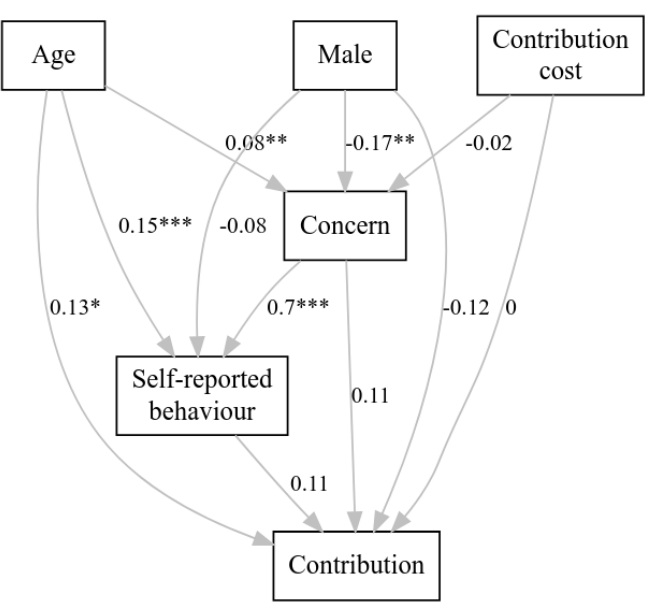

\section{B) Conservatives}

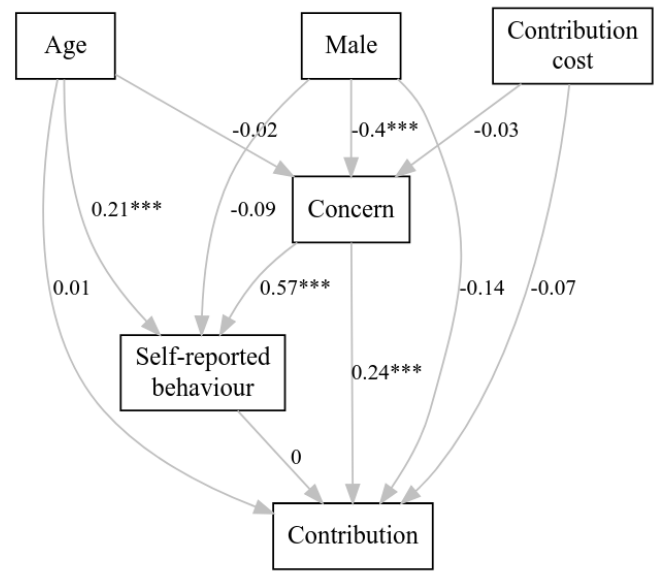

Figure 4: Separate estimates of the structural equation models for liberals (A) and conservatives (B). All variables were standardised.

useful to predict the latter. The evaluation and planning of environmental policies on the basis of surveys is thus an often problematic practice. Our results also point to a general limitation of surveys in the study of environmental behaviour: since environmental questions are politically and ethically loaded, the resulting strong social desirability bias (Sebbane \& Costa 2018; Carrington et al. 2010; Krumpal 2011) makes self-reported behaviour in this context even less reliable. The real attitude-behaviour gap may hence be even larger than the one usually found in surveys. Compared to traditional research in social sciences, mainly based on surveys and interviews, randomised behavioural experiments and related methods represent valuable instruments to understand factors leading to real-world environmental behaviour (Farjam et al. 2018, 2019; van den Bergh 2008; Stern et al. 2016).

We also found that the attitude-behaviour gap in an environmental context varies strongly with demographic characteristics. Environmental concern proved to be an important variable to predict self-reported behaviour but only for conservatives it held a significant relation with actual contributions. For liberals, the contribution was mediated more by the political affiliation itself than by their concern. This pattern seems plausible in the light of the strong politicisation of environmental issues in the USA (McCright et al. 2014; Hornsey et al. 2018), which may push liberals to abide to the perceived pro-evironment norms of their group independently of their personal beliefs (Fielding \& Hornsey 2016). For conservatives, a group where a strong environmental concern clearly does not represent the modal case, the correlation between concern and actual contributions was instead significant.

An interesting finding is that the costs of environmental behaviour did not mediate the relationship between concern and contributions, neither in the whole sample nor in any of the two political groups. This contradicts the so-called low-cost hypothesis of environmental behaviour (Diekmann \& Preisendörfer 1998, 2003), along with previous research supporting it in experimental (Farjam et al. 2019) and field settings (Kaiser \& Schultz 2009; Keuschnigg \& Kratz 2017). One possible explanation for this discrepancy is that the experimental setting in Farjam et al. (2019) included several rounds of interaction in larger groups, along with a shared goal to be reached to avoid the "collective risk" posed by climate change. This relatively complex experimental setup may have led to more strategic thinking among participants, including a rational weighting of contribution costs vs. expected benefits of investments in climate change mitigation (Milinski et al. 2006). The contribution task used in our experiment was much simpler, which may have enhanced the effect 
of a social norm for contribution and pushed participants to ignore the related cost, something that has been found to occur in field settings as well (Keuschnigg \& Kratz 2017). An alternative explanation is that, even in the treatment where 100 ECU were worth 10 USD, the resulting cost was not high enough to produce measurable effects. Participants in Farjam et al. (2019) indeed played for up to 40 USD, which means that a higher USD / ECU ratio may be needed to produce the same result in our setting.

Environmental behaviour and in particular climate change mitigation is, of course, far more complex in the real world than the contribution task in our experiment. The simplicity of our contribution task, along with the fact that there was no possibility for participants to free-ride on others' contributions may have increased the overall contribution level. The existence of a collective action problem is often assumed to be a key in explaining the insufficient commitment of citizens to climate change mitigation (Dietz et al. 2003; Barrett \& Dannenberg 2014; Milinski et al. 2006). While we have no way to test this hypothesis with current data, it suggests that the discrepancies between environmental concern and actual behaviour may be even larger in situations characterized by strategic interaction. In part, this effect was found in Farjam et al. (2019) but needs more systematic tests to be confirmed. In addition, it is unclear how robust our findings can be against changes in the cultural and political environment. In particular, the experiment should be replicated in countries where beliefs on climate change are less politicised and hence less affected by political group norms.

Acknowledgments The research presented in this article was supported by the Linnaeus University Center for Data Intensive Sciences and Applications, DISA (http://lnu. se/disa). The authors gratefully acknowledge the useful comments made by Marc Keuschnigg and Andreas Diekmann on a previous version of the manuscript.

Author contributions. M.F. and G.B. planned the research and wrote the paper. M.F. coded and conducted the experiment. G.B. analysed the data.

\section{References}

Barrett, S. \& Dannenberg, A. (2014). Sensitivity of collective action to uncertainty about climate tipping points. Nature Climate Change, 4, 36-39.

Bolsen, T. \& Druckman, J. N. (2015). Counteracting the politicization of science. Journal of Communication, 65(5), 745-769.

Carrington, M. J., Neville, B. A., \& Whitwell, G. J. (2010). Why ethical consumers don't walk their talk: Towards a framework for understanding the gap between the ethical purchase intentions and actual buying behaviour of ethically minded consumers. Journal of Business Ethics, 97(1), 139-158.

Carrington, M. J., Neville, B. A., \& Whitwell, G. J. (2014). Lost in translation: Exploring the ethical consumer intention-behavior gap. Journal of Business Research, 67(1), 2759-2767.

Chen, D. L., Schonger, M., \& Wickens, C. (2016). oTree: An open-source platform for laboratory, online, and field experiments. Journal of Behavioral and Experimental Finance, 9, 88-97.

Cruz, S. M. (2017). The relationships of political ideology and party affiliation with environmental concern: A meta-analysis. Journal of Environmental Psychology, 53, 81-91.

Diekmann, A. \& Preisendörfer, P. (1998). Environmental behavior: Discrepancies between aspirations and reality. Rationality and Society, 10(1), 79-102.

Diekmann, A. \& Preisendörfer, P. (2003). Green and greenback: The behavioral effects of environmental attitudes in low-cost and high-cost situations. Rationality and Society, 15(4), 441-472.

Dietz, T., Ostrom, E., \& Stern, P. C. (2003). The struggle to govern the commons. Science, 302, 1907-1912.

Farjam, M. (2020). The bandwagon effect in an online experiment with real political organisations. International Journal of Public Opinion Research, edaa008. 
Farjam, M., Nikolaychuk, O., \& Bravo, G. (2018). Does risk communication really decrease cooperation in climate change mitigation? Climatic change, 149(2), 147-158.

Farjam, M., Nikolaychuk, O., \& Bravo, G. (2019). Experimental evidence of an environmental attitudebehavior gap in high-cost situations. Ecological Economics, 166, 106434.

Fielding, K. S. \& Hornsey, M. J. (2016). A social identity analysis of climate change and environmental attitudes and behaviors: Insights and opportunities. Frontiers in Psychology, 7.

Flynn, R., Bellaby, P., \& Ricci, M. (2009). The value-action gap in public attitudes towards sustainable energy: the case of hydrogen energy. The Sociological Review, 57, 159-180.

Hassan, L. M., Shiu, E., \& Shaw, D. (2014). Who says there is an intention-behaviour gap? assessing the empirical evidence of an intention-behaviour gap in ethical consumption. Journal of Business Ethics, 136(2), 219-236.

Hornsey, M. J., Harris, E. A., \& Fielding, K. S. (2018). Relationships among conspiratorial beliefs, conservatism and climate scepticism across nations. Nature Climate Change, 8(7), 614-620.

Jerolmack, C. \& Khan, S. (2014). Talk is cheap: Ethnography and the attitudinal fallacy. Sociological Methods \& Research, 43(2), 178-209.

Kaiser, F. G. \& Schultz, P. W. (2009). The attitude-behavior relationship: A test of three models of the moderating role of behavioral difficulty1. Journal of Applied Social Psychology, 39(1), 186-207.

Keuschnigg, M. \& Kratz, F. (2017). Thou shalt recycle: How social norms of environmental protection narrow the scope of the low-cost hypothesis. Environment and Behavior, 50(10), 1059-1091.

Kollmuss, A. \& Agyeman, J. (2002). Mind the gap: Why do people act environmentally and what are the barriers to pro-environmental behavior? Environmental Education Research, 8(3), 239-260.

Krumpal, I. (2011). Determinants of social desirability bias in sensitive surveys: a literature review. Quality \& Quantity, 47(4), 2025-2047.

Lange, F. \& Dewitte, S. (2019). Measuring pro-environmental behavior: Review and recommendations. Journal of Environmental Psychology, 63, 92-100.

Lorenzoni, I., Nicholson-Cole, S., \& Whitmarsh, L. (2007). Barriers perceived to engaging with climate change among the UK public and their policy implications. Global Environmental Change, 17(3-4), 445-459.

McCright, A. M., Xiao, C., \& Dunlap, R. E. (2014). Political polarization on support for government spending on environmental protection in the USA, 1974-2012. Social Science Research, 48, 251-260.

Milfont, T. L. \& Duckitt, J. (2010). The environmental attitudes inventory: A valid and reliable measure to assess the structure of environmental attitudes. Journal of Environmental Psychology, 30(1), 80-94.

Milinski, M., Semmann, D., Krambeck, H.-J., \& Marotzke, J. (2006). Stabilizing the earth's climate is not a losing game: Supporting evidence from public goods experiments. Proceedings of the National Academy of Science USA, 103(11), 3994-3998.

Peattie, K. (2010). Green consumption: Behavior and norms. Annual Review of Environment and Resources, 35(1), 195-228.

R Core Team (2018). R: A Language and Environment for Statistical Computing. Vienna, Austria: R Foundation for Statistical Computing.

Sebbane, M. \& Costa, S. (2018). Food leftovers in workplace cafeterias: An exploratory analysis of stated behavior and actual behavior. Resources, Conservation and Recycling, 136, 88-94.

Stern, P. C., Sovacool, B. K., \& Dietz, T. (2016). Towards a science of climate and energy choices. Nature Climate Change, 6(6), 547-555.

van den Bergh, J. C. (2008). Environmental regulation of households: An empirical review of economic and psychological factors. Ecological Economics, 66(4), 559-574.

Whitmarsh, L. (2009). Behavioural responses to climate change: Asymmetry of intentions and impacts. Journal of Environmental Psychology, 29(1), 13-23.

Wynes, S. \& Nicholas, K. A. (2017). The climate mitigation gap: education and government recommendations miss the most effective individual actions. Environmental Research Letters, 12(7), 074024. 


\section{A Appendix}

\section{A.1 Instructions}

Thank you for participating in an experiment on decision making. It is important that you remain concentrated and do not engage in other distracting activities. This experiment will consist of a questionnaire on your attitude towards environmental issues and a donation decision. The experiment is expected to take 10 minutes.

For your participation in the experiment you will get a bonus and the size of the bonus depends on how much of your potential bonus you are willing to donate to an environmental cause in the donation decisions.

Within this studies all transfers are made with ECU (experimental currency unit). To you, each ECU is worth $0.01 \$$ ( 1 cent).

All ECUs that you donate will be given to an developmental project at the UN climate fund offset.climateneutralnow.org. All the donations made on the website allow buying energy efficient appliances and reducing $\mathrm{CO} 2$ emissions. At the moment, the most efficient project needs $0.5 \$$ for offsetting $2000 \mathrm{lbs}$ of $\mathrm{CO} 2$. If you want to, you can enter your email address at the end of the experiment to receive proof of the donation to the UN climate fund.

When you are done reading the instructions, click the button below. You will then have to answer a number of comprehension questions. Your answers will be checked by the computer and you will only be able to be rewarded for your participation if you answer at least $80 \%$ correctly.

\section{A.2 Treatment sample descriptives}

\begin{tabular}{ccccc}
\hline $\begin{array}{c}\text { N.of } \\
\text { observations }\end{array}$ & $\begin{array}{c}\text { Treatment } \\
\text { (Cents/ECU) }\end{array}$ & $\begin{array}{c}\text { Age } \\
\text { avg. (SD) }\end{array}$ & $\begin{array}{c}\text { Males } \\
\text { proportion }\end{array}$ & $\begin{array}{c}\text { Left-right scale } \\
\text { avg. (SD) }\end{array}$ \\
\hline 76 & 1 & $39.1(13.3)$ & 0.50 & $4.4(3.1)$ \\
86 & 2 & $39.8(12.9)$ & 0.51 & $3.9(3.0)$ \\
81 & 3 & $37.7(12.0)$ & 0.51 & $4.2(2.8)$ \\
91 & 4 & $37.9(12.2)$ & 0.60 & $3.7(3.0)$ \\
66 & 5 & $38.1(11.9)$ & 0.50 & $4.0(3.0)$ \\
67 & 6 & $39.4(12.2)$ & 0.60 & $4.0(3.4)$ \\
103 & 7 & $41.4(12.9)$ & 0.46 & $3.8(3.2)$ \\
52 & 8 & $37.9(12.2)$ & 0.48 & $3.5(2.8)$ \\
91 & 9 & $37.6(10.5)$ & 0.56 & $4.1(3.2)$ \\
92 & 10 & $38.6(12.5)$ & 0.50 & $3.3(3.0)$ \\
\hline
\end{tabular}

Table 1: Descriptive statistics per treatment

\section{A.3 Measures of environmental concern and self-reported behaviour}

To measure environmental concern, we used selected item from the the Environmental Attitudes Inventory (EAI), which includes several scales capturing different dimensions of environmental concern and behaviour and has been extensively tested on different cultures (Milfont \& Duckitt 2010). Our environmental concern factor builds on the Environmental threat and Ecocentric concern scales. The self-reported behaviour factor is instead based on the Personal conservation behaviour scale. Each of the EAI scales below includes 10 items measured on a 7-point agreement scale ( $1=$ strongly disagree, $7=$ strongly agree). The $(\mathrm{R})$ symbol means that the scale should be reversed in the analysis.

\section{Environmental threat}

1. If things continue on their present course, we will soon experience a major ecological catastrophe. 
2. The earth is like a spaceship with very limited room and resources.

3. The balance of nature is very delicate and easily upset.

4. When humans interfere with nature it often produces disastrous consequences.

5. Humans are severely abusing the environment.

6. The idea that we will experience a major ecological catastrophe if things continue on their present course is misguided nonsense. (R)

7. I cannot see any real environmental problems being created by rapid economic growth. It only creates benefits. (R)

8. The idea that the balance of nature is terribly delicate and easily upset is much too pessimistic. (R)

9. I do not believe that the environment has been severely abused by humans. (R)

10. People who say that the unrelenting exploitation of nature has driven us to the brink of ecological collapse are wrong. (R)

\section{Ecocentric concern}

1. The idea that nature is valuable for its own sake is naïve and wrong (R).

2. It makes me sad to see natural environments destroyed.

3. Nature is valuable for its own sake.

4. One of the worst things about overpopulation is that many natural areas are getting destroyed.

5. I do not believe protecting the environment is an important issue. (R)

6. Despite our special abilities humans are still subject to the laws of nature.

7. It makes me sad to see forests cleared for agriculture.

8. It does NOT make me sad to see natural environments destroyed. (R)

9. I do not believe nature is valuable for its own sake. (R)

10. I don't get upset at the idea of forests being cleared for agriculture. (R)

\section{Personal conservation behaviour}

1. I could not be bothered to save water or other natural resources. (R)

2. I make sure that during the winter the heating system in my room is not switched on too high.

3. In my daily life I'm just not interested in trying to conserve water and/or power. (R)

4. Whenever possible, I take a short shower in order to conserve water.

5. I always switch the light off when I don't need it on any more.

6. I drive whenever it suits me, even if it does pollute the atmosphere. (R)

7. In my daily life I try to find ways to conserve water or power.

8. I am NOT the kind of person who makes efforts to conserve natural resources. (R)

9. Whenever possible, I try to save natural resources.

10. Even if public transportation was more efficient than it is, I would prefer to drive my car. (R)

\section{A.4 Factor analysis}

Factor analysis (FA) was performed using the $R$ 3.6.2 platform (R Core Team 2018) with the psych package to estimate the factors. Table 2 shows the factor loadings along with the proportion of variance explained by each factor.

\section{A.5 Structural equation modelling}

Structural equation modelling (SEM) was performed using the $R$ 3.6.2 platform (R Core Team 2018) with the lavaan package to estimate the models. The tables below shows the coefficient estimates and statistics for the models presented in Figures 2 and 4. 


\begin{tabular}{lcccc}
\hline EAI item & $\begin{array}{c}\text { Environmental } \\
\text { threat }\end{array}$ & $\begin{array}{c}\text { Ecocentric } \\
\text { Concern }\end{array}$ & $\begin{array}{c}\text { Self-reported } \\
\text { Behaviour }\end{array}$ & $\begin{array}{c}\text { Environmental } \\
\text { Concern }\end{array}$ \\
\hline Environmental threat 1 & 0.85 & & & 0.76 \\
Environmental threat 2 & 0.64 & & & 0.58 \\
Environmental threat 3 & 0.74 & & & 0.69 \\
Environmental threat 4 & 0.78 & & & 0.75 \\
Environmental threat 5 & 0.86 & & & 0.81 \\
Environmental threat 6 (R) & 0.75 & & & 0.71 \\
Environmental threat 7 (R) & 0.79 & & & 0.78 \\
Environmental threat 8 (R) & 0.81 & & & 0.77 \\
Environmental threat 9 (R) & 0.78 & & & 0.77 \\
Environmental threat 10 (R) & 0.86 & 0.71 & & 0.82 \\
Ecocentric concern 1 (R) & & 0.78 & & 0.60 \\
Ecocentric concern 2 & & 0.67 & & 0.71 \\
Ecocentric concern 3 & & 0.70 & & 0.72 \\
Ecocentric concern 4 & & 0.72 & & 0.69 \\
Ecocentric concern 5 (R) & & 0.59 & & 0.54 \\
Ecocentric concern 6 & & 0.70 & & 0.68 \\
Ecocentric concern 7 & & 0.67 & & 0.72 \\
Ecocentric concern 8 (R) & 0.77 & & 0.54 \\
Ecocentric concern 9 (R) & & & 0.68 & 0.72 \\
Ecocentric concern 10 (R) & & & 0.56 & \\
Personal conservation behaviour 1 (R) & & & 0.70 & \\
Personal conservation behaviour 2 & & & 0.66 & \\
Personal conservation behaviour 3 (R) & & & 0.51 & \\
Personal conservation behaviour 4 & & & 0.50 & \\
Personal conservation behaviour 5 & & & 0.82 & \\
Personal conservation behaviour 6 (R) & & & 0.81 & \\
Personal conservation behaviour 7 & & & 0.35 & \\
Personal conservation behaviour 8 (R) & & & & \\
Personal conservation behaviour 9 & & & & \\
Personal conservation behaviour 10 (R) & & & & \\
\hline Explained variance & & & & \\
\hline & & & & \\
\hline
\end{tabular}

Table 2: Loadings and proportion of explained variance of factors. Items where reversed when indicated by $(\mathrm{R})$

\begin{tabular}{llrrrr}
\hline Outcome & Predictor & Estimate & SE & $z$ & $p$ \\
\hline Concern & Left-wing & 0.529 & 0.029 & 18.311 & 0.000 \\
& Age & 0.042 & 0.029 & 1.454 & 0.146 \\
& Male & -0.246 & 0.057 & -4.284 & 0.000 \\
& Contribution cost & -0.029 & 0.029 & -1.007 & 0.314 \\
\hline \multirow{2}{*}{ Self-reported behaviour } & Concern & 0.591 & 0.032 & 18.301 & 0.000 \\
& Left-wing & -0.033 & 0.031 & -1.062 & 0.288 \\
& Age & 0.184 & 0.026 & 6.966 & 0.000 \\
& Male & -0.091 & 0.053 & -1.709 & 0.087 \\
\hline Contribution & Self-reported behaviour & 0.049 & 0.046 & 1.067 & 0.286 \\
& Concern & 0.241 & 0.050 & 4.806 & 0.000 \\
& Contribution cost & -0.036 & 0.034 & -1.045 & 0.296 \\
& Left-wing & -0.126 & 0.041 & -3.074 & 0.002 \\
& Age & 0.054 & 0.036 & 1.531 & 0.126 \\
& Male & -0.129 & 0.070 & -1.846 & 0.065 \\
\hline Adjusted Goodness of Fit & & 0.998 & & & \\
\hline & & & & &
\end{tabular}

Table 3: SEM coefficient estimates (all observations). All variables were standardised. 
A. Liberals

\begin{tabular}{llrrrr}
\hline Outcome & Predictor & Estimate & SE & $z$ & $p$ \\
\hline \multirow{2}{*}{ Concern } & Age & 0.080 & 0.029 & 2.806 & 0.005 \\
& Male & -0.168 & 0.056 & -2.971 & 0.003 \\
& Contribution cost & -0.017 & 0.028 & -0.618 & 0.536 \\
\hline \multirow{2}{*}{ Self-reported behaviour } & Concern & 0.700 & 0.066 & 10.680 & 0.000 \\
& Age & 0.149 & 0.038 & 3.956 & 0.000 \\
& Male & -0.083 & 0.075 & -1.110 & 0.267 \\
\hline \multirow{2}{*}{ Contribution } & Self-reported behaviour & 0.107 & 0.068 & 1.565 & 0.118 \\
& Concern & 0.106 & 0.101 & 1.045 & 0.296 \\
& Contribution cost & 0.000 & 0.050 & 0.003 & 0.997 \\
& Age & 0.130 & 0.052 & 2.471 & 0.013 \\
& Male & -0.116 & 0.102 & -1.136 & 0.256 \\
\hline Adjusted Goodness of Fit & & 0.999 & & & \\
\hline
\end{tabular}

\section{B. Conservatives}

\begin{tabular}{llrrrr}
\hline Concern & Age & -0.021 & 0.053 & -0.402 & 0.688 \\
& Male & -0.403 & 0.106 & -3.808 & 0.000 \\
& Contribution cost & -0.028 & 0.053 & -0.528 & 0.598 \\
\hline \multirow{2}{*}{ Self-reported behaviour } & Concern & 0.574 & 0.035 & 16.408 & 0.000 \\
& Age & 0.207 & 0.037 & 5.563 & 0.000 \\
& Male & -0.088 & 0.076 & -1.168 & 0.243 \\
\hline \multirow{2}{*}{ Contribution } & Self-reported behaviour & 0.002 & 0.062 & 0.035 & 0.972 \\
& Concern & 0.236 & 0.056 & 4.179 & 0.000 \\
& Contribution cost & -0.072 & 0.046 & -1.555 & 0.120 \\
& Age & 0.006 & 0.048 & 0.118 & 0.906 \\
& Male & -0.144 & 0.095 & -1.519 & 0.129 \\
\hline \multirow{2}{*}{ Adjusted Goodness of Fit } & & 0.993 & & & \\
\hline
\end{tabular}

Table 4: Separate SEM estimates for (A) liberals and (B) conservatives. All variables were standardised. 